\title{
The Greenland Ice Core Chronology 2005, 15-42 ka. Part 1: constructing the time scale
}

\author{
Katrine K. Andersen ${ }^{a, *}$, Anders Svensson ${ }^{\text {a }}$, Sigfus J. Johnsen ${ }^{\mathrm{a}}$, Sune O. Rasmussen ${ }^{\mathrm{a}}$, \\ Matthias Bigler $^{\mathrm{a}}$, Regine Röthlisberger ${ }^{\mathrm{b}}$, Urs Ruth ${ }^{\mathrm{c}}$, Marie-Louise Siggaard-Andersen ${ }^{\mathrm{a}}$, \\ Jørgen Peder Steffensen ${ }^{\mathrm{a}}$, Dorthe Dahl-Jensen ${ }^{\mathrm{a}}$, Bo M. Vinther ${ }^{\mathrm{a}}$, Henrik B. Clausen ${ }^{\mathrm{a}}$ \\ a Ice and Climate Research, Niels Bohr Institute, University of Copenhagen, Denmark \\ ${ }^{\mathrm{b}}$ British Antarctic Survey, High Cross, Madingley Road, Cambridge, CB3 OET, UK \\ ${ }^{\mathrm{c}}$ Alfred-Wegener-Institut for Polar and Marine Research, Bremerhaven, Germany
}

Received 30 March 2006; accepted 6 August 2006

\begin{abstract}
The Greenland Ice Core Chronology 2005, GICC05, is extended back to $42 \mathrm{ka}$ b2k (before 2000 AD), i.e. to the end of Greenland Stadial 11. The chronology is based on independent multi-parameter counting of annual layers using comprehensive high-resolution measurements available from the North Greenland Ice Core Project, NGRIP. These are measurements of visual stratigraphy, conductivity of the solid ice, electrolytical melt water conductivity and the concentration of $\mathrm{Na}^{+}, \mathrm{Ca}^{2+}, \mathrm{SO}_{4}^{2-}, \mathrm{NO}_{3}^{-}, \mathrm{NH}_{4}^{+}$. An uncertainty estimate of the time scale is obtained from identification of 'uncertain' annual layers, which are counted as $0.5 \pm 0.5$ years. The sum of the uncertain annual layers, the so-called maximum counting error of the presented chronology ranges from $4 \%$ in the warm interstadial periods to $7 \%$ in the cold stadials. The annual accumulation rates of the stadials and interstadials are on average one-third and half of the present day values, respectively, and the onset of the Greenland Interstadials 2,3 , and 8 , based on 20 year averaged $\delta^{18} \mathrm{O}$ values, are determined as 23,340, 27,780, and 38,220 yr b2k in GICC05.
\end{abstract}

(C) 2006 Elsevier Ltd. All rights reserved.

\section{Introduction}

Very accurate dating is essential in order to draw maximum benefit from the large amount of climate data evolving from the palaeoclimate community. Ice cores are palaeo archives reaching several hundred thousand years back in time (Greenland Ice-Core Project (GRIP) Members, 1993; Bender et al., 1994; Petit et al., 1999; EPICA community members, 2004; NGRIP Members, 2004), and under optimal conditions, the age-depth relationship is relatively simple and well-understood as compared to many other sediments. The annual accumulation rate at the drill sites of deep ice cores in Greenland and Antarctica spans from a few centimetres of ice equivalent per year in Central Antarctica to more than half a metre of ice equivalent per year e.g. in central Southern Greenland.

\footnotetext{
${ }^{*}$ Corresponding author. Tel.: + 4535320530 ; fax: +4535365357 .

E-mail address: kka@gfy.ku.dk (K.K. Andersen).
}

Deep ice cores have been dated by annual layer counting, flow models, wiggle matching to existing time scales or a combination hereof. Annual layer counting has mostly been applied at high accumulation sites and for the upper parts of the ice cores, where layer thinning due to ice flow is limited. Ice flow models have been applied to most ice cores drilled on the large ice sheets, but the accuracy is highest for ice cores drilled at optimal sites with little flow disturbance. Wiggle matching to existing ice core time scales or orbitally tuned marine records has often been used as a first indication of the age of an ice core, especially for Antarctic ice cores reaching half a million years and more back in time. Greenland ice cores generally have a higher temporal resolution than Antarctic ice cores, and thus have a higher potential for accurate dating. The so far most used stratigraphic ice core chronology for the last glacial period is that of the GISP2 ice core (Meese et al., 1994; Alley et al., 1997; Meese et al., 1997), based on visual stratigraphy (VS), high resolution Laser Light Scattering 
measurements, and the conductivity of the solid ice. The most used timescales for the GRIP ice core are the model timescales ss09 (Johnsen and Dansgaard, 1992) and ss09sea (Johnsen et al., 2001). A very thorough review of the different timescales applied for the GRIP and GISP2 ice cores was given by Southon (2004).

Recently a stratigraphic dating initiative, the Greenland Ice Core Chronology 2005, based on the DYE-3, GRIP and NGRIP Greenland ice cores constructed a timescale back to $14.8 \mathrm{ka}$ (Rasmussen et al., 2006; Vinther et al., 2006). The most recent part back to $7.9 \mathrm{ka}$ is based on high resolution isotopic measurements from several Greenland ice cores, but beyond this age isotopic diffusion obliterates the annual cycle in the isotopic records (Vinther et al., 2006). Rasmussen et al. (2006) presented the continuation of the multi-parameter dating through the lateglacial oscillations, i.e. back to $14,776 \mathrm{yr}$ b2k (before $2000 \mathrm{AD}$, i.e. corresponding to $14,726 \mathrm{yr} \mathrm{BP}$ ). The early Holocene part of the dating is based on high resolution data from both the GRIP and the NGRIP ice cores, while the glacial part is solely based on high resolution measurements from the NGRIP ice core. In this work we present the continued multi-parameter dating from 14,777 to $41,761 \mathrm{yr} b 2 \mathrm{k}$, covering the Greenland Interstadials (GI) 2-10 and Greenland Stadials (GS) 2-10 within Marine Isotope Stages (MIS) 2 and 3. The numbering of Greenland stadials and interstadials in this work is according to Björck et al. (1997) and Walker et al. (1999). A thorough comparison of the presented chronology with other comparable timescales such as the modelled ss09sea timescale and the GISP2 timescale is given in the companion paper by Svensson et al. (2006).

\section{High resolution data sets from the NGRIP ice core}

The NGRIP ice core from North Central Greenland (Dahl-Jensen et al., 2002; NGRIP Members, 2004) is very well suited for stratigraphic dating of the last glacial period. Due to melting at the base of the ice sheet at NGRIP the thinning of the annual ice layers is considerably less than for other Greenland deep ice cores, and the annual layer thicknesses on average remain around $7 \mathrm{~mm}$ ice $\mathrm{yr}^{-1}$ throughout the deepest part of the core. The effect of the decreased thinning is strongest below $\sim 2500 \mathrm{~m}$, but together with the moderately low accumulation and the different strain regime at NGRIP it implies that the annual layer thickness throughout most of the glacial period at NGRIP is higher than at sites such as GRIP and GISP2, where no basal melting occurs. Fig. 1 shows the modelled annual layer thicknesses (see Appendix A) for the GRIP and NGRIP cores. Below about $1850 \mathrm{~m}$ corresponding to $24 \mathrm{ka} \mathrm{b} 2 \mathrm{k}$ the layer thicknesses at NGRIP become larger than at GRIP.

\subsection{High resolution data sets}

Continuous high resolution measurements have been obtained over a large part of the NGRIP ice core. For the glacial part these measurements include Continuous Flow Analysis (CFA) of chemical impurities, insoluble dust and electrolytical conductivity on continuously melted ice samples (Röthlisberger et al., 2000; Ruth et al., 2003; Bigler, 2004), Electrical Conductivity Measurement (ECM) on the solid ice (Hammer, 1980; Dahl-Jensen et al., 2002) and the VS grey-scale profile (Svensson et al., 2005). All

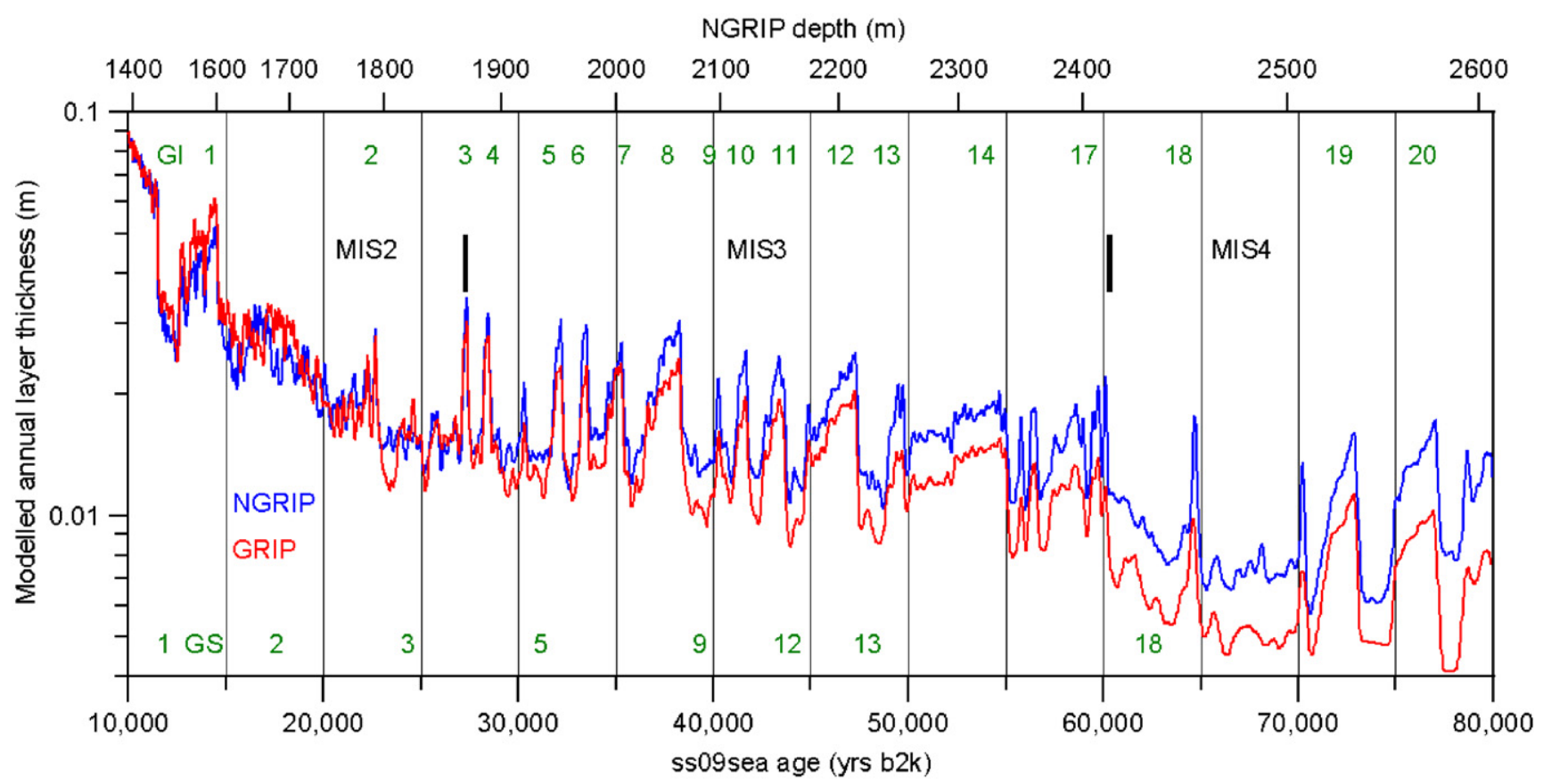

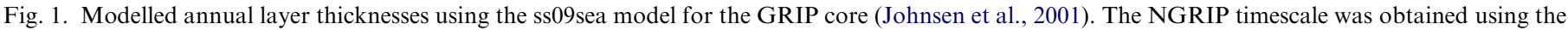

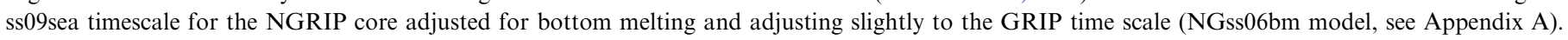


measurements were performed on $1.65 \mathrm{~m}$ sections of the core at a time. The CFA measurements comprise insoluble dust, electrolytical melt water conductivity (hereafter conductivity), and the water-soluble species $\left[\mathrm{Ca}^{2+}\right]$, $\left[\mathrm{Na}^{+}\right],\left[\mathrm{NH}_{4}^{+}\right],\left[\mathrm{SO}_{4}^{2-}\right],\left[\mathrm{NO}_{3}^{-}\right],\left[\mathrm{H}_{2} \mathrm{O}_{2}\right]$ and $[\mathrm{HCHO}]$. They were recorded at $1 \mathrm{~mm}$ resolution, but the effective resolution (the shortest wavelength that can be identified from the data) is between 10 and $25 \mathrm{~mm}$ (Röthlisberger et al., 2000; Rasmussen et al., 2006). However, due to postdepositional effects, the annual cycle of $\mathrm{HCHO}$ and $\mathrm{H}_{2} \mathrm{O}_{2}$ is not preserved in the ice and those two components cannot be used for stratigraphic dating in the glacial. The ECM record was also sampled at $1 \mathrm{~mm}$ resolution and has an effective resolution of about $4 \mathrm{~mm}$ (Rasmussen et al., 2006). The VS is based on digital imaging of the ice core (Svensson et al., 2005). Due to the very high resolution especially the VS record shows a high degree of sub-annual variations which can make the identification of the annual layers more complicated. Hence the VS data have here been smoothed with a Gaussian filter of about $2 \mathrm{~mm}$. This is much narrower than the annual layers, and the layer identification is thus not influenced.

When combining different sets of measurements, relative depth control is important. For the VS record a digital camera is mounted above the ice on a moving trolley, and the depth control for this record is very accurate. CFA measurements of the different species were carried out in parallel on the melt water from a $3 \mathrm{~cm}$ by $3 \mathrm{~cm}$ slab of the ice core. The absolute accuracy of the depth control is better than $1 \mathrm{~cm}$, and offsets between the different records are limited to some millimetres. The depth control of the ECM is less accurate than for the other measurements, as this measurement is performed by pulling a set of electrodes by hand over the cleaned ice surface. Experience from this work shows that gliding offsets up to about $5 \mathrm{~cm}$ over a section of $1.65 \mathrm{~m}$ may be found, but it is generally accurate to within a few centimetres.

\subsection{Data quality}

As the annual layers in the investigated part of the ice core are relatively thin, sections of missing data could potentially make the layer identification impossible. However, in the presented part of the NGRIP ice core data loss is minimal, and the multi-parameter approach means that data gaps in individual data sets used for the dating are rarely significant. The VS measurements and ECM were performed on a cleaned horizontal surface of the core without further sampling, and without significant data loss across core breaks. For the CFA measurement short sections of missing data occur at core breaks where some ice had to be removed when de-contaminating the core. Regular cuts at the ends of the samples only give rise to very short breaks in the data sets but around irregular breaks a few centimetres of data may be missing as the sample pieces had to be trimmed. This means that a few annual layers may be missing in the CFA records over the breaks. The data gaps across breaks are normally smaller for ECM than for CFA, and VS is measured across the core breaks without data gaps. The breaks give rise to characteristic peaks in VS at the position of the breaks, but the total dating uncertainty across core breaks is small.

Over the investigated depth interval between 1604 and $2128 \mathrm{~m}$, corresponding to $15-42 \mathrm{ka} \mathrm{b} 2 \mathrm{k}$, data gaps of more than $0.5 \mathrm{~m}$ are rare for the records used. Data gaps in $\left[\mathrm{SO}_{4}^{2-}\right]$ and $\left[\mathrm{Na}^{+}\right]$amount to $12-13 \mathrm{~m}$, corresponding to $2.5 \%$. For the other records $0.1-1.3 \%$ of the data are missing, except for VS which is continuously measured over the whole section presented. For two sections of about $0.5 \mathrm{~m}$ length (1623-1623.35 $\mathrm{m}$ and $1753.4-1754 \mathrm{~m})$ coincident data gaps are found for several CFA records. Increased uncertainty in the dating due to data gaps is reflected in the error estimate given, and is thus largely accounted for.

\section{Identification of annual layers}

Annual layers in Greenland ice cores can be detected from the seasonal variations in the concentrations of impurities deposited in the ice and thus in the measured chemical composition and conductivity (Hammer et al., 1978; Steffensen, 1988; Beer et al., 1991; Whitlow et al., 1992; Ram and Koenig, 1997). It has also been shown that visible stratigraphy and variations in physical properties of the ice can reveal the annual layering (Alley et al., 1997; Meese et al., 1997; Svensson et al., 2005).

\subsection{Counting strategy}

In this study the annual layers were identified by two experienced investigators, who both contributed to the dating of the period 8-15 ka using the same type of records from the NGRIP ice core (Rasmussen et al., 2006). Based on this experience each investigator individually counted the investigated period, whereafter the two counts were compared. Whenever discrepancies in a section were of the same order or larger than the error estimate assigned by the investigators the annual layer marks were re-examined and placed in co-operation between the investigators.

As seen in Fig. 1 annual layers just below the onset of the Bølling, i.e. below $1600 \mathrm{~m}$, are expected to be at most $3 \mathrm{~cm}$ thick, which is comparable to the Younger Dryas section. Deeper in the core significantly thinner layers are expected, and the identification of annual layers between 1600 and $2120 \mathrm{~m}$ depth had to be based mostly on the best resolved records. These are the VS, ECM and conductivity measurements, whereas some of the CFA measurements like insoluble dust and partly $\left[\mathrm{Ca}^{2+}\right]$ were disregarded due to insufficient resolution.

The error estimate for the GICC05 time scale is introduced through 'uncertain annual layers' which are counted as $0.5 \pm 0.5$ years in the same manner as described by Rasmussen et al. (2006). Uncertain annual layers are 
assigned when only some of the used records display an annual signal, when the relative timing of seasonal peaks is inconsistent with our interpretation, or if it is in some other way judged that the probability of a certain feature being an annual layer lies somewhere between $25 \%$ and $75 \%$. The accumulated error obtained by summing up the uncertain annual layers is called the maximum counting error (MCE). For $N$ uncertain layers it amounts to $N \times 0.5$ years.

\subsection{Annual layer signature}

A very distinct signature of the annual cycle in the concentration of chemical species in recent Greenland ice has been described by several authors (Steffensen, 1988; Beer et al., 1991; Whitlow et al., 1992). As described by Rasmussen et al. (2006) a signature consistent with that of the recent Holocene was found for the warmest parts of the last glacial termination, between 10.3 and $14.8 \mathrm{ka}$ b2k. A peak in $\left[\mathrm{Na}^{+}\right]$derived from sea salt aerosol is observed in late winter. Spring is characterized by a strong dust peak which is also reflected in $\left[\mathrm{Ca}^{2+}\right]$, and the summer season may be recognized by increased levels of first $\left[\mathrm{SO}_{4}^{2-}\right]$, and then $\left[\mathrm{NO}_{3}^{-}\right]$and $\left[\mathrm{NH}_{4}^{+}\right]$. The VS record may contain more than one peak per year, and each visible layer is believed to represent a single depositional event (Svensson et al., 2005). The ECM record reflects $\left[\mathrm{H}^{+}\right]$in the ice, and is reported in units of $\mu$ equiv $/ \mathrm{kg}$. Dips are associated mostly with peaks of $\left[\mathrm{NH}_{4}^{+}\right]$and $\left[\mathrm{Ca}^{2+}\right]$. The conductivity merely reflects the total content of ions in the melt water, and can to some degree be seen as the sum of the impurity concentrations. As described above, the different impurity concentrations peak in different seasons in warm periods and this is reflected by multiple peaks within a year in the conductivity, ECM, and to some degree VS records. In the colder Younger Dryas period Rasmussen et al. (2006) found that these seasonal differences disappear, and that most species peak at the same time of the year. Although this is not always the case for $\left[\mathrm{NH}_{4}^{+}\right]$, it has the effect that interpretation of the annual signal in conductivity, ECM, and VS becomes more straightforward in the cold periods than during the warmer periods.

For the identification of the annual layers in this work all relevant records were plotted at $1 \mathrm{~mm}$ resolution against depth, as depicted in Figs. 2 and 3. Small depth offsets were eliminated before identifying the annual layers by shifting especially the ECM record to match the VS record. As seen in Figs. 2 and 3 there is a clear correspondence between the
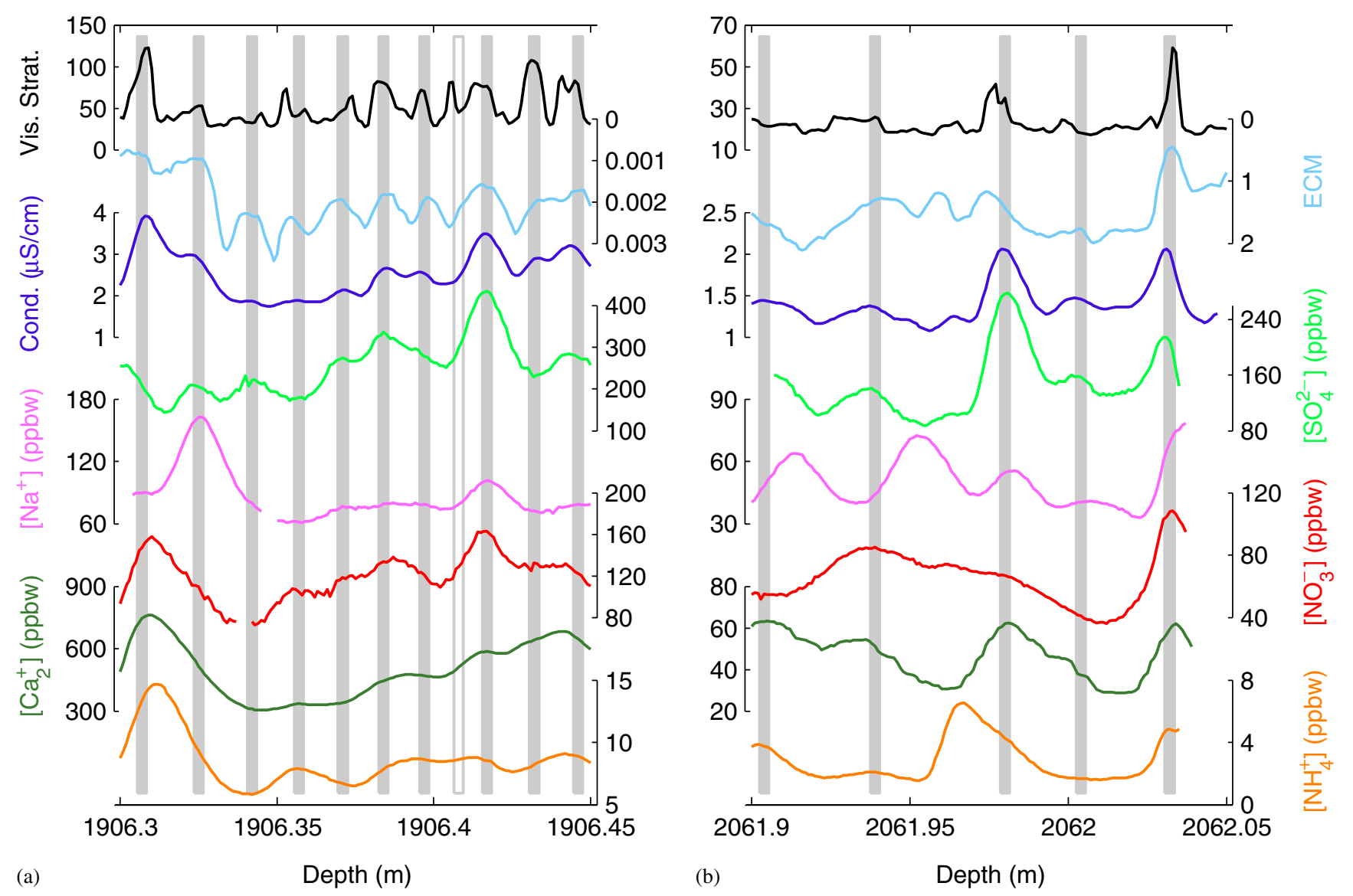

Fig. 2. Examples of annual layer identification are shown for (a) the cold stadial GS-5 about $30 \mathrm{ka}$ b2k and (b) the warm interstadial GI-8 about 38 ka b2k. In the cold stadials annual layers are mostly identified from peaks in VS, conductivity and ECM. In the warmer interstadials the annual layers are better resolved in the chemical components, whereas VS often has multiple peaks within an annual layer. Annual layer marks are normally set in conductivity maxima and uncertain annual layers are marked with open bars, certain annual layers with filled bars. Note that the scale for ECM has been reversed. 


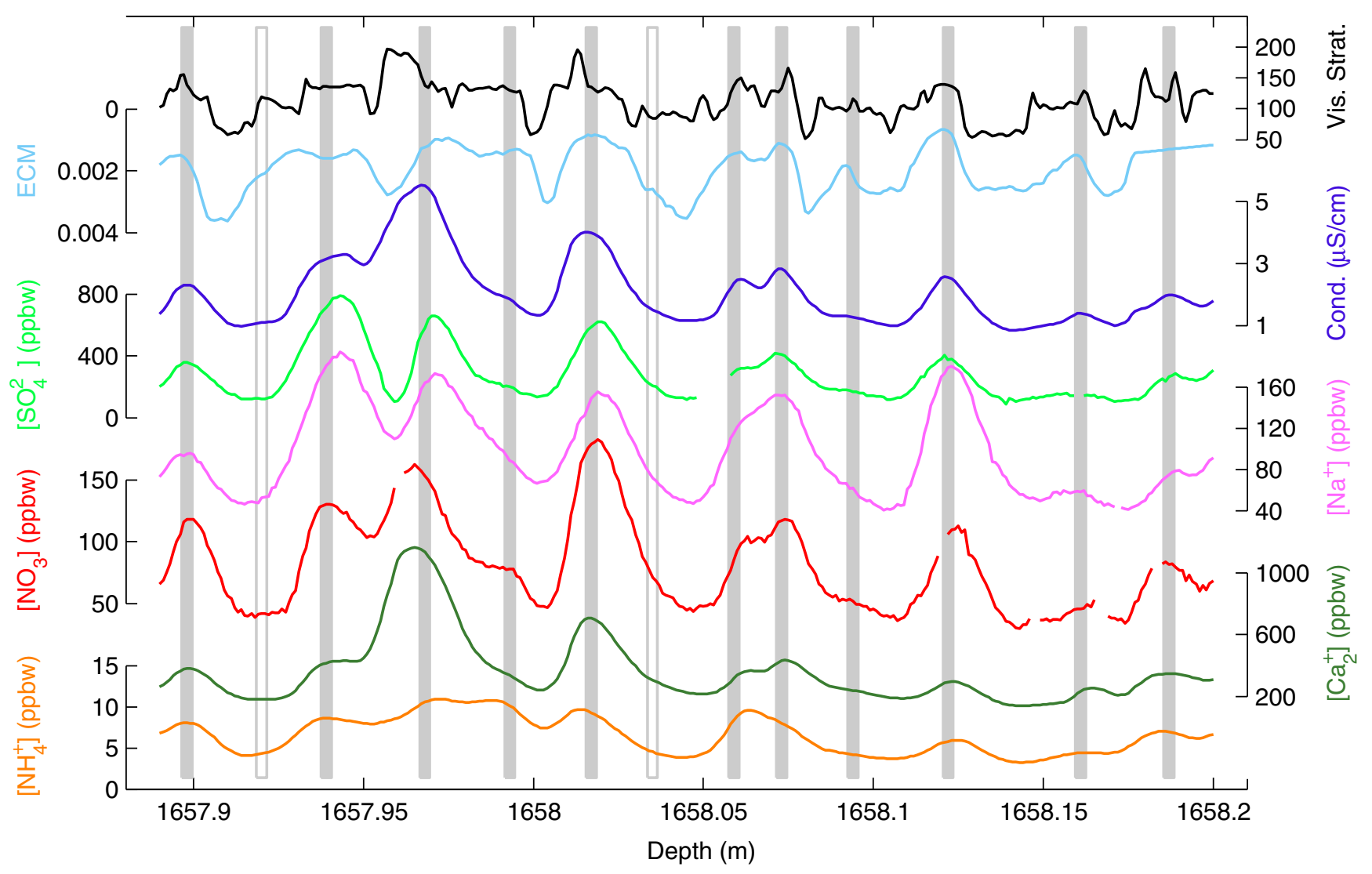

Fig. 3. Example of annual layer identification in a $0.3 \mathrm{~m}$ sequence from MIS2, $17 \mathrm{ka} \mathrm{b} 2 \mathrm{k}$. The annual layers in this region are about $2.5 \mathrm{~cm}$ thick. Uncertain annual layers are marked with open bars, certain annual layers with filled bars. Note that the ECM scale has been reversed.

ECM, and VS signals, and to some degree the conductivity, although at a somewhat lower resolution. For the identification of the annual layers $40-50 \mathrm{~cm}$ of data were plotted at a time.

In Figs. 2 and 3 grey bars indicate annual markers, which have been placed in conductivity maxima. Open bars indicate uncertain layers, i.e. $0.5 \pm 0.5$ year. Fig. 2 a shows a section from a cold stadial period, where the annual layer thickness is around $1.5 \mathrm{~cm}$. Although the individual annual peaks are not resolved in the chemical records the marked and distinguishable peaks in VS and conductivity and marked minima in ECM (note the reversed scale) indicate that the maxima in all chemical records are synchronous, as was also observed for the cold Younger Dryas period. It may be noted that the very high levels of alkaline dust in the glacial ice (Ruth et al., 2003) do not obliterate the seasonal signal in ECM during the coldest periods. In Fig. 2a an uncertain year is placed at $1906.41 \mathrm{~m}$. This marker indicates that the wide peak at $1906.42 \mathrm{~m}$ could as well be 2 years as suggested by the extra peak in VS, and the shoulder in ECM. Fig. $2 b$ shows the annual layering at $2062 \mathrm{~m}$ depth within the very warm part of the GI-8 period. The annual layer thickness is approximately twice that of the stadial period shown in Fig. 2a, and the layering is clearly distinguishable in $\left[\mathrm{SO}_{4}^{2-}\right]$, and $\left[\mathrm{Na}^{+}\right]$, where the maxima are synchronous on the right hand side of the plot, around $2062 \mathrm{~m}$. These annual layers are also distinguishable in VS, ECM, conductivity, and partly $\left[\mathrm{NH}_{4}^{+}\right]$, whereas the $\left[\mathrm{NO}_{3}^{-}\right]$record is highly diffused in this section. The $\left[\mathrm{Ca}^{2+}\right]$ signal is also highly diffused and moreover hampered by noise in this particular section. The two annual layers on the left hand side show a clear seasonal offset, with the maximum in $\left[\mathrm{Na}^{+}\right]$lying clearly before the maxima in the other records. This seasonal offset resembles what is found in the Holocene and in parts of the Allerød and Bølling periods. The seasonal offset clearly hampers the interpretation of the VS, ECM and conductivity records. The strong peak in $\left[\mathrm{NH}_{4}^{+}\right]$at $2061.97 \mathrm{~m}$ is an example of occasional $\left[\mathrm{NH}_{4}^{+}\right]$spikes that are not necessarily part of the seasonal cycle. It is also reflected in the ECM curve.

During the cold MIS2 period, which includes the coldest part of the last glacial period (Fig. 1), the annual peaks are mostly synchronous for the different species. Nevertheless short sections and even individual years with a seasonal shift in the peaks occur from time to time. This is exemplified in Fig. 3 where the annual peaks are mostly in phase for the different species, but slight offsets in the maxima are found for the two annual markers around $1657.95 \mathrm{~m}$. Here peaks in $\left[\mathrm{SO}_{4}^{2-}\right]$, and $\left[\mathrm{Na}^{+}\right]$clearly occur earlier than for the other species. This is also reflected by broad peaks in conductivity, ECM, and VS, as compared 
to the more distinct peaks on the right hand side of the plot. Uncertain layers are assigned at 1657.92 and $1658.04 \mathrm{~m}$ depth. At both depths peaks are found in VS, and shoulders in ECM and partly conductivity, but it is not clear from the records of the chemical impurities that these are actual annual layers.

A satisfactory explanation for the difference between cold periods with coincident maxima in most profiles and warmer periods with a more frequent seasonal pattern is so far not evident. Based on model simulations it has been suggested, that winter precipitation in Greenland may have been severely reduced during the coldest parts of the last glacial period (Krinner et al., 1997; Werner et al., 2000). This could imply that most impurities are efficiently deposited in spring to summer when the first precipitation events occur. If the seasonality during the remaining part of the year was preserved, the species that in warm periods peak in summer or autumn, like $\left[\mathrm{NO}_{3}^{-}\right]$and $\left[\mathrm{NH}_{4}^{+}\right]$, should still have maxima later in the year than the species that in warm periods are deposited early in the year $\left(\left[\mathrm{Na}^{+}\right]\right.$, $\left[\mathrm{Ca}^{2+}\right]$, dust and partly $\left.\left[\mathrm{SO}_{4}^{2-}\right]\right)$. We, however, find synchronous maxima for all species. Another explanation could be changed long-range transport towards the Greenland Ice Sheet during the coldest parts of the glacial. In the data presented here we observe shifts between the two modes of deposition on a year-to-year basis, and across the transitions between stadials and interstadials, a shift in the major signature of the annuals occurs within very few years. This points towards a feature caused by changes in atmospheric circulation. Bromwich et al. (2004) suggested a split jet stream pattern around the Laurentide Ice Sheet during the LGM. Favourable transport north or south of the Laurentide during different time periods could possibly be an explanation for the feature observed here. The issue of changes in seasonal deposition merits further investigations, possibly with the use of high resolution General Circulation Models. A complete understanding is, however, not crucial for the stratigraphic dating.

\subsection{Resolution of the measured species}

Diffusion and mixing during measurement of the different impurity records acts to obliterate the high frequency variations. As shown by Svensson et al. (2005) the very highly resolved VS record could be modified to resemble most of the glacial CFA measurements by folding with an appropriate Gaussian filter, i.e. applying artificial diffusion. The number of layers identifiable from an individual record is highly dependent on the measurement resolution, as higher resolved records introduce more details about individual depositional events, and thus may not show a unique annual peak. This point was tested here by simply counting the number of peaks, for the individual records over $50 \mathrm{~m}$ of ice core, covering GI-3 and GI-4, without considering any information from the other species in contrast to the multi-parameter approach. Fig. 4 clearly illustrates the measurement resolution of the

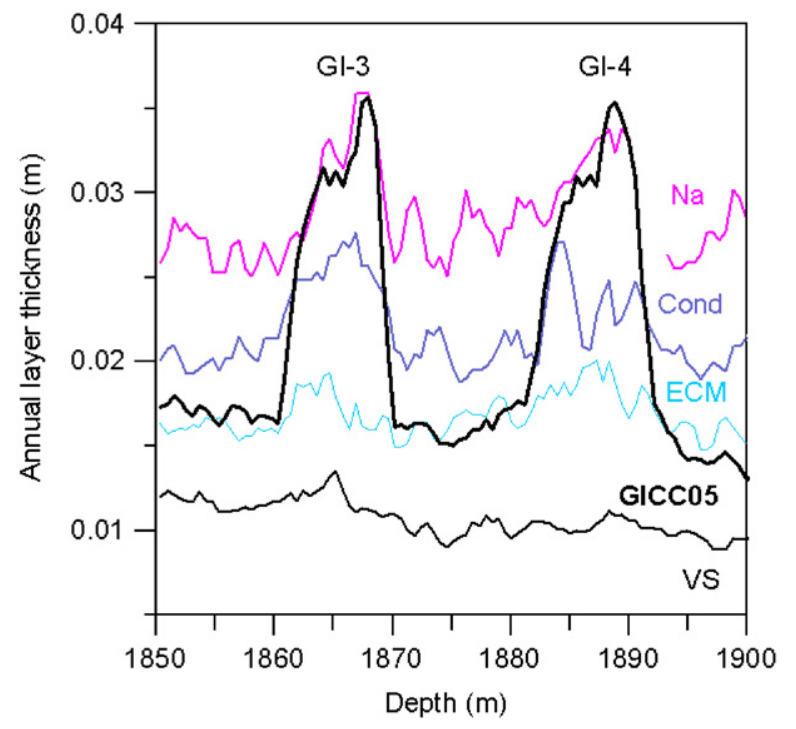

Fig. 4. The apparent annual layer thickness across GI-3 and GI-4, when layer counting was based only on the peaks in one record at a time. None of the applied records alone suffices to correctly represent the annual layers (see details in Section 3.3).

different measured species. The VS signal is very highly resolved, and sub-annual peaks are registered which are attributable to larger precipitation events and during warm periods to the different timing of the maxima for different impurities (Svensson et al., 2005). The resolution of the VS record is always sufficient to resolve the annual layers, but the sub-annual layering may mask the annual signal, and make it hard to identify. However, in the cold periods minor peaks are normally easily grouped into annuals by visual inspection. The resolution of the ECM profile is appropriate to identify the annual layers in the cold periods. In the warmer interglacials the seasonal offset in the different species makes the ECM signal harder to interpret, and in fact using ECM only, the apparent layer thickness across the stadials and interstadials is almost constant (Fig. 4). The conductivity profile is subject to the same limitations as the ECM signal, in that multiple peaks occur within one annual layer during warm periods. In the colder stadials the resolution is marginal for the identification of annuals layers, but the profile may support the counting based on VS and ECM. The sodium profile represents most chemical species, in that annual peaks are reliably represented during interglacials, but the thin stadial layering is not resolved, and the apparent annual layer thickness using sodium alone only decreases slightly in the stadial period. The interpretation of annual layers in the presented work is thus based on our experience of the different seasonal behaviour of the different species during cold and warm periods. This interpretation is supported and facilitated by the shape of the VS and ECM curves which is very dependent on the relative timing of seasonal peaks in the chemical components. The annual layer counting across the stadials and interstadials is thus only possible in a multi-parameter approach. 


\section{Uncertainty estimate}

As described by several authors (Alley et al., 1997; Rasmussen et al., 2006; Vinther et al., 2006) errors and counting uncertainty in stratigraphic ice core dating may derive from several sources, such as imperfect core stratigraphy, core loss, data loss, and insufficient resolution and misinterpretation of the records. As discussed in Section 2.2 core loss is negligible in this part of the NGRIP ice core, and the stratigraphy is barely hampered by the short sections of data loss. The data resolution is always sufficient for annual layer identification in VS and ECM, although it becomes marginal for the conductivity measurements in the coldest periods. In general, lower reliability of the dating due to missing data or marginal data resolution is always reflected in the number of uncertain year marks, and thus in the MCE.

\subsection{Possible interpretation bias}

Misinterpretation of the data and insufficient resolution potentially comprise larger problems in the glacial section of the GICC05 stratigraphy presented here, than in the more recent sections, because annual layers are thinner in the glacial. A direct assessment of the possible interpretation bias is, however, not possible. Comparisons with other available timescales for this period such as presented by Svensson et al. (2006), may give an indication of the bias. Shorter term disagreements with both the GISP2 stratigraphy and the modelled ss09sea time scale are found, but they are mostly attributed to shortcomings in those timescales. The overall agreement with reference horizons such as the Laschamp event $41 \mathrm{ka}$ b2k is good and within the error margins.

The reproducibility of the counting strategy applied here was tested, in that annual layers in the interval $1600-1860 \mathrm{~m}$ were identified independently by both investigators. This resulted in, respectively, 12,878 years with an MCE of 612.5 years $(4.8 \%)$ versus 12,714 years with an MCE of 631 years $(5 \%)$, which is a difference of 164.5 years corresponding to $1.3 \%$, i.e. considerably less than the MCE. Over the stadial-interstadial variations of MIS3 annual layer thicknesses in the stratigraphy have subsequently been compared to the modelled layer thicknesses displayed in Fig. 1 (see also Svensson et al., 2006). Although there are clear differences, both in the mean layer thickness over sections and the temporal variations, the generally good agreement indicates that our interpretation of the annual signal is reasonable.

Although we cannot definitely claim that the stratigraphy presented here may not be biased through misinterpretation of the annual layering, the applied interpretation is in line with experiences from the shallower parts of the NGRIP ice core, and it provides results which are in general agreement with independent dating efforts (see also Svensson et al., 2006).

\subsection{Discussion of error estimate}

Lotter and Lemcke (1999) reviewed methods and problems in the counting of biochemical varves. Some of their conclusions are also applicable to counting of annual layers in ice cores. They suggest that the counting error be estimated through either repeated counts by one analyst or several analysts counting the same section in the same manner. This is the method that was applied for the GISP2 stratigraphy (Alley et al., 1997; Meese et al., 1997). The error may be estimated as the root mean squared error of the different counts, but this estimate is too optimistic because it does not take into account that the counters are not necessarily completely independent, as they may have the same bias. The maximum and minimum deviations should therefore also be given (Lotter and Lemcke, 1999). The rationale of reporting maximum and minimum deviations in a way corresponds to the MCE given here, which is simply the accumulated sum of the uncertain layers counted as $0.5 \pm 0.5$ years. We here found that the difference in multiple counting was generally either comparable to or lower than the MCE indicated by the experienced analysts, and we chose to apply the MCE as the maximum deviation. We consider the MCE to be a conservative error estimate.

Around the onset of GI- 8 at $38.2 \mathrm{ka} \mathrm{b} 2 \mathrm{k}$ the MCE is $1450 \mathrm{yr}$, which means that from present day back to $38.2 \mathrm{ka}$ 36,750 certain and 2900 uncertain annual layers have been identified. Under the assumption that the data resolution is sufficient to resolve annual layers, that missing annual layers are not a major problem, and that loss of data and core is considered negligible, the MCE constitutes a very conservative error estimate because it is obtained by linear error accumulation. A total error of $1450 \mathrm{yr}$ at the onset of GI-8 would mean that either all or none of the uncertain years identified through almost $40 \mathrm{ka}$, including interglacial, stadial and interstadial periods are true annual layers. This must be regarded as highly unlikely.

A different approach to estimate the error would be to assume that the uncertain years are completely uncorrelated and thus binomially distributed. By definition the uncertain marks are set when it is estimated that the probability $p$ of having a year is $0.25<p<0.75$. Therefore, ideally one could simply calculate the standard uncertainty as $\frac{1}{2} \cdot \operatorname{sqrt}(N)$, where $N$ is the number of uncertain annual layers, i.e. $N=2 \cdot M C E$. This approach would lead to a $1 \sigma$ error of 27 years at the onset of GI-8. However, as also discussed by Rasmussen et al. (2006) this must be regarded an unrealistically low error because in general the uncertain layer marks are likely not to be completely independent, but rather somewhat biased, e.g. in sections where the data resolution is limited or in sections where multiple peaks within an annual layer appear frequently for some of the species.

Because there is a need for providing a reasonable error estimate that is comparable to the $1 \sigma$ error applied in absolute dating, we propose the application of an 


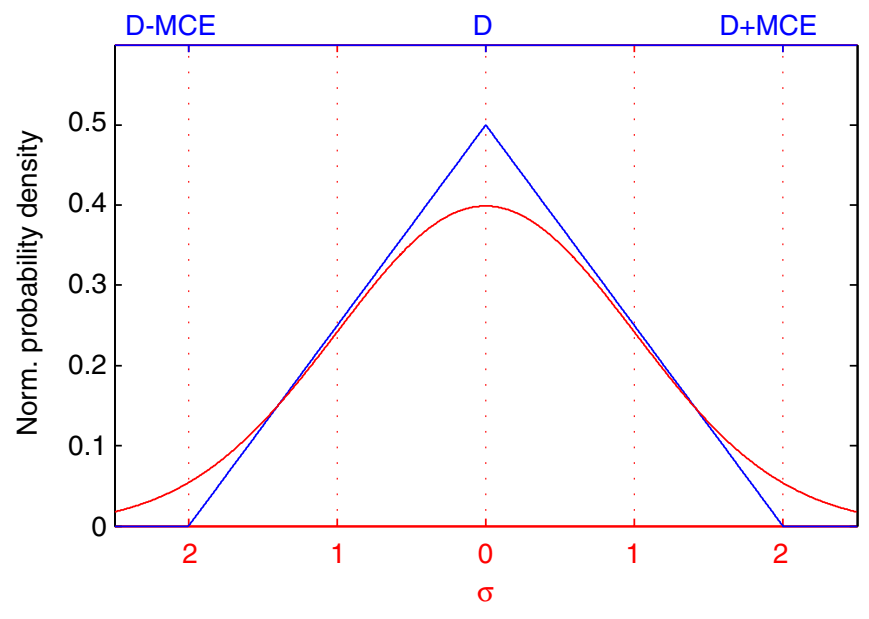

Fig. 5. Approximation of a triangular distribution (blue) with a Gaussian distribution (red). The half-width of the triangle, the MCE of the counting, corresponds to $2 \sigma$ of the Gaussian.

alternative error estimate. As a reasonable and simple compromise between the two distributions presented above we assume that the probability distribution of ages around an age $D$, is a triangle that is centered on $D$ and for which the length of the baseline is equal to the number of uncertain annual layer marks (Fig. 5). This leaves room for a large degree of correlation between the uncertain years, and at the same time is consistent with MCE being the maximum counting error. A triangle can be rather well approximated with a Gaussian and we use the $2 \sigma$ error of a corresponding Gaussian distribution as an apparent maximum error estimate for the triangular distribution. As seen in Fig. 5 a Gaussian distribution with $2 \sigma$ equal to half the width of the triangle makes a good approximation to the triangle. We thus suggest to regard MCE as the $2 \sigma$ error. We stress that this is a pragmatic approach and not a true $\sigma$ uncertainty, but we find this to be a good compromise between the very conservative MCE and the very restrictive $\frac{1}{2} \cdot \operatorname{sqrt}(N)$ error. It still allows for a quite significant bias in the counting. At the onset of GI- 8 the apparent $1 \sigma$ error is 724 years, which we consider a very reasonable error estimate.

\section{Results and discussion}

The investigated section from 1607 to $2128.5 \mathrm{~m}$ depth in the NGRIP ice core represents the time period from 14,777 to $41,761 \mathrm{yr}$ b2k. The NGRIP $\delta^{18} \mathrm{O}$ profile and the annual layer thicknesses derived from GICC05 are displayed in Fig. 6 together with the relative and absolute counting error. Annual layer thicknesses are closely related to the climatic state as indicated by the $\delta^{18} \mathrm{O}$ profile, e.g. over the stadial-interstadial shifts, but smaller variations in $\delta^{18} \mathrm{O}$ such as in GS-2 are not reflected in the annual layer thickness. A comparison of the timescale derived here with the ss09sea model timescale is presented by Svensson et al. (submitted for publication). The observed layer thickness for GS-2 is around $2.5 \mathrm{~cm}$, but it changes abruptly across
GI-2 to $1.5-2 \mathrm{~cm}$ in GS-3. Thin layers of around $1.5 \mathrm{~cm}$ are found for the stadial periods GI-3 to GI-10, whereas the layers in the interstadial periods GI-3 to GI-10 on average are about twice as thick.

The onsets of the interstadials determined as the midpoint of the sharp increase in 20 years averaged $\delta^{18} \mathrm{O}$ (Fig. 6) are given in Table 1 together with the $1 \sigma$ counting uncertainty, as defined in Section 4.2. These uncertainties are comparable to uncertainties given for other dating methods in this period, but one of the main strengths of a stratigraphic timescale such as GICC05 is in the differential dating, i.e. the small uncertainty in the duration of climatic periods. The duration of the individual stadial-interstadial variations is also given in Table 1 . The $1 \sigma$ uncertainty in duration ranges from 1.5 to $3.4 \%$, i.e. from 27 years for the short (1300 year) GI-10 to GS-10 period to 206 years for the 8660 years long GI-2 to GS-2 period.

The counting error (Fig. 6) generally varies oppositely to the layer thickness such that higher uncertainties are found for the thinner stadial layers than for the thicker interstadial layers (Fig. 6). This difference arises because the chemical records do not resolve the thin stadial layers such that the counting is based on fewer parameters. On average we find a $1 \sigma$ uncertainty of $2.4 \%$ in GS-2, $3.2 \%$ in GS-3 to GS-10, and $1.9 \%$ in GI-3 to GI-10. The counting uncertainty in GS-2 is relatively low as compared to the other stadials due to the somewhat thicker annual layers in this period.

In order to be able to compare the annual layer thicknesses in the depth interval investigated here to those of the Holocene (Andersen et al., 2006, accepted) and the last glacial termination (Rasmussen et al., 2006) the obtained annual layer thicknesses have been strain corrected based on the NGss06bm model (see Appendix A). We thus derive estimated annual accumulation rates, $\lambda_{\text {corr }}$, in ice equivalent, representing the actual amount of accumulation per year. Fig. 7 displays the distribution of $\lambda_{\text {corr }}$ for the single years in GS-2, and the stadials and interstadials of the remaining period. The distributions are based on 7400 years in GS-2, 12,470 stadial years and 2920 interstadial years in GI-3 to GI-10. For the latest 2000 years of the Holocene and also in climatically relatively stable periods of the last glacial termination annual layers have been found to be approximately lognormally distributed, i.e. the logarithm of $\lambda_{\text {corr }}$ being normally distributed (Andersen et al., 2006, accepted; Rasmussen et al., 2006), which is in line with the annual accumulation being the sum of positive independent precipitation events. We see here that this is also the case for similar climatic states during the last glacial. The median of $\lambda_{\text {corr }}$, which corresponds to $10^{\mu}$ (Fig. 7) is in the following denoted $\left\langle\lambda_{\text {corr }}\right\rangle$. It is in Table 2 compared to results for the periods investigated by Rasmussen et al. (2006). $\left\langle\lambda_{\text {corr }}\right\rangle$ for the stadial periods is $5.5-6.2 \mathrm{~cm}$, i.e. about one-third of the present day accumulation rate of $19 \mathrm{~cm}$ (NGRIP Members, 2004). During GI-3 to GI-10 $\left\langle\lambda_{\text {corr }}\right\rangle$ is $10.1 \mathrm{~cm}$, around half of today's value. The early Holocene period has 


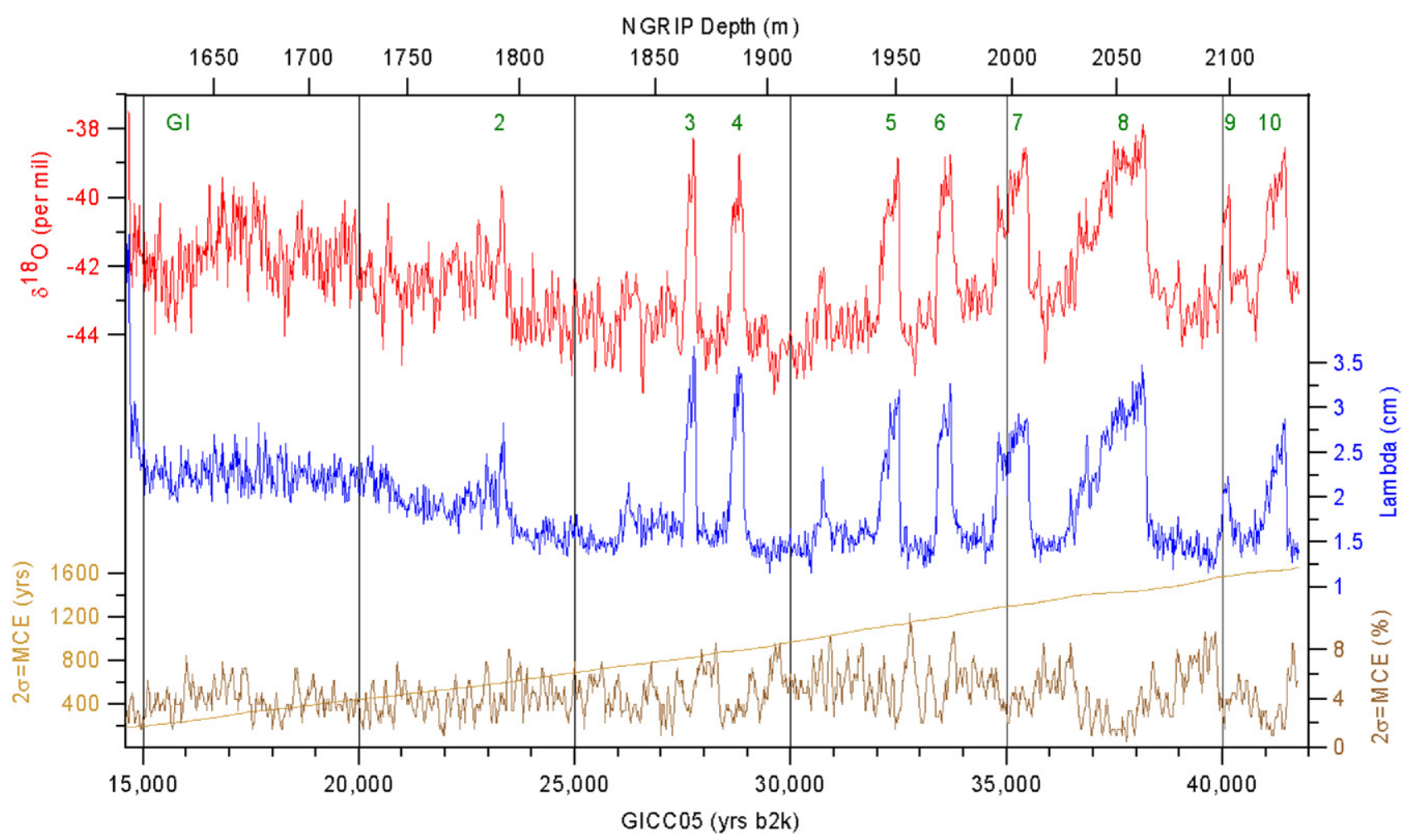

Fig. 6. The GICC05 time scale over the glacial period from 14,777 to $41,761 \mathrm{yr}$ b2k $(14,727 \mathrm{BP}-41,711 \mathrm{yr} \mathrm{BP})$. The red curve displays NGRIP $\delta^{18} \mathrm{O}$ variations on the new time scale. The associated annual layer thickness (blue) is closely related to the climate signal reflected by $\delta^{18} \mathrm{O}$. The relative counting error (dark brown) is generally larger in cold stadials than in warm interstadials. The accumulated absolute counting error (light brown) begins at a value of MCE $=190$ years, which is inherited from the upper parts of GICC05 (Rasmussen et al., 2006; Vinther et al., 2006). The curves are displayed as 20 year averages, and the relative counting error is determined over 100 years.

Table 1

The onset of Greenland Interstadials based on the GICC05 timescale

\begin{tabular}{lll}
\hline Onset of & Years $\mathrm{b} 2 \mathrm{k} \pm 1 \sigma(=0.5 \cdot \mathrm{MCE})$ & Years to next onset \\
\hline GI-1 & $14,680 \pm 93$ & $2976 \pm 43^{\mathrm{a}}$ \\
GI-2 & $23,340 \pm 298$ & $8660 \pm 206$ \\
GI-3 & $27,780 \pm 416$ & $4440 \pm 118$ \\
GI-4 & $28,900 \pm 449$ & $1120 \pm 33$ \\
GI-5 & $32,500 \pm 566$ & $3600 \pm 117$ \\
GI-6 & $33,740 \pm 606$ & $1240 \pm 40$ \\
GI-7 & $35,480 \pm 661$ & $1740 \pm 55$ \\
GI-8 & $38,220 \pm 724$ & $2740 \pm 64$ \\
GI-9 & $40,160 \pm 790$ & $1940 \pm 66$ \\
GI-10 & $41,460 \pm 817$ & $1300 \pm 27$ \\
\hline
\end{tabular}

The onset has been visually determined as the midpoint of the sharp increase in 20 year averaged $\delta^{18} \mathrm{O}$. Uncertainties do not reflect any uncertainty in the determination of the onsets, only in the timescale. See text for details.

${ }^{\mathrm{a}}$ Onset of the Holocene 11,703 $\pm 50 \mathrm{yr}$ b2k from Rasmussen et al. (2006).

somewhat lower accumulation than today, and $\left\langle\lambda_{\text {corr }}\right\rangle$ for the Bølling period is significantly higher than for the remaining interstadials. $\left\langle\lambda_{\text {corr }}\right\rangle$ for the Younger Dryas is somewhat higher than for GS-2, and an abrupt change in layer thickness occurs over GI-2 with GS-3 to GS-10 showing distinctly thinner layers than GS-2 (Figs. 6 and 3 in Svensson et al., 2006). The distributions shown in Fig. 7 imply that the probability of a layer thickness being either greater than $2 \cdot\left\langle\lambda_{\text {corr }}\right\rangle$ or smaller than $0.5 \cdot\left\langle\lambda_{\text {corr }}\right\rangle$ is only $1.7 \%$ for GS2, $2.2 \%$ for GS-3 to GS- 10 and $1.1 \%$ for GI-3 to GI-10 substantiating the assumption that the ice core contains an unbroken stratigraphical sequence of annual layers. The final GICC05 timescale was made by counting every second uncertain layer mark as a year, and the analysis of the distribution of annual layers has also been carried out on the series obtained by including either all or none of the uncertain layers. In both cases the distributions become less symmetric (not shown), and an over-representation of thinner/thicker layers is found. This supports our interpretation of the MCE as a very conservative estimate of uncertainty.

A potential criticism of ice core chronologies is the question whether annual layers could be missing, either due to wind scouring having removed annual layers, or precipitation being absent over a full year. Based on the dating accuracy of historically well-known volcanic markers (Vinther et al., 2006) we know that this is not the case for present day at NGRIP. It has been shown that the Holocene stratigraphy at NGRIP compares very well with that from higher accumulation sites (Andersen et al., 2006, accepted for publication; Rasmussen et al., 2006; Vinther et al., 2006). During the glacial period the accumulation at NGRIP was reduced to $0.29-0.56$ of the present value (Table 2). These accumulation rates are comparable to 
several Antarctic sites at present. Nevertheless the high resolution VS record (Svensson et al., 2005) still indicates several precipitation events per year during the coldest periods. The present accumulation at the GISP2 site is $24 \mathrm{~cm}$ of ice (Meese et al., 1997) and thus higher than at NGRIP. The correspondence between GICC05 and the GISP2 dating over MIS2 is very good and within our uncertainty estimate (Fig. 2 in Svensson et al., 2006). This
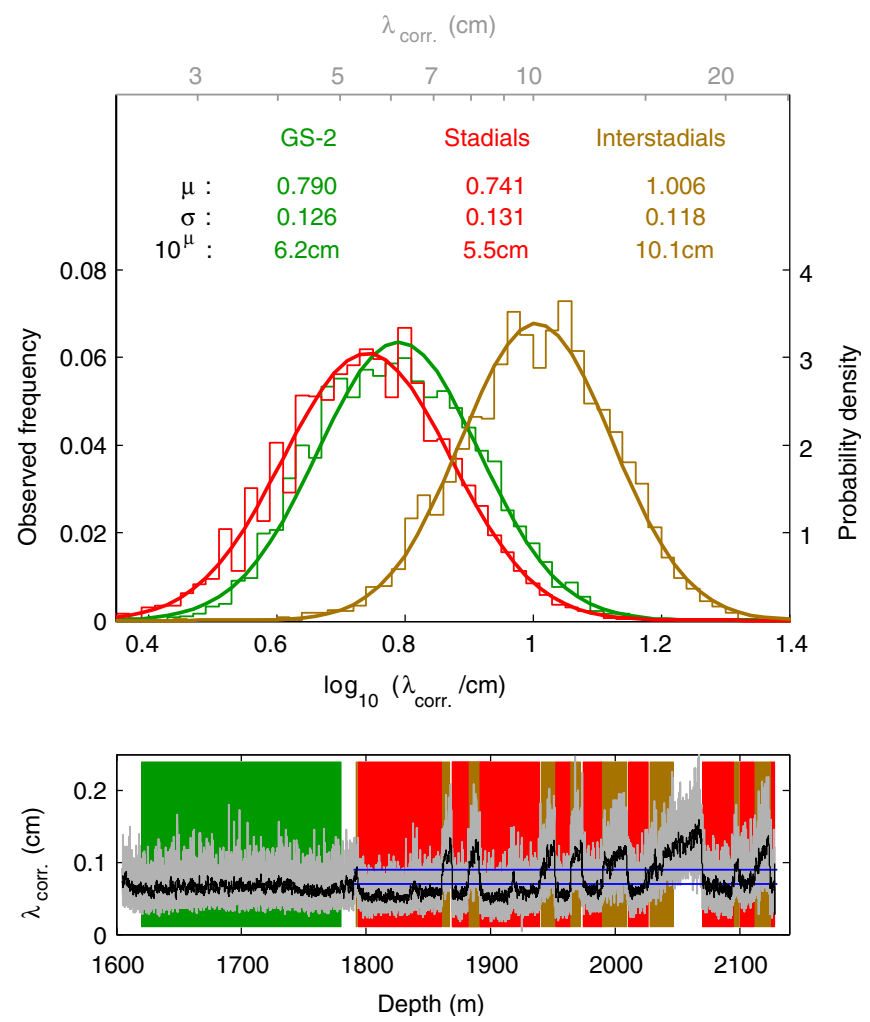

Fig. 7. The upper panel displays the distribution of strain corrected annual layer thicknesses, $\lambda_{\text {corr }}$, for the cold GS-2 period and for the remaining stadials (GS-3 to GS-10) and interstadials (GI-3 to GI-10) taken as one. The lower panel shows the distinction between the different periods. In order to avoid influence from non-stable climatic periods transitional periods are not included and the stadials are chosen as years with 20 years running mean $\lambda_{\text {corr }}$ between 3 and $7 \mathrm{~cm}$, and interstadials between 9 and $12 \mathrm{~cm}$. The transitional bounds are shown by the blue horizontal lines. makes us confident that none of the chronologies can be significantly biased by missing annual layers. We believe that the larger disagreement in MIS3 can be attributed to problems in the GISP2 dating, when identifying annual layers across the stadials and interstadials based on only a few parameters. The complicated shifts in the annual signal in that period makes multi-parameter analysis imperative. Moreover the very good fits between $\log _{10}\left(\lambda_{\text {corr }}\right)$ and the Gaussian distributions in Fig. 7 indicate (a) no absence of thin layers, the match is equally good for high and low values and (b) the probability for even half the average accumulation in GS-2 is below $2 \%$. The possible error due to missing layers is thus well within the given uncertainty.

\section{Summary and conclusion}

We have here presented the continuation of GICC05 over the time interval from 15 to $42 \mathrm{ka}$. The chronology is based on a high resolution multi-parameter dataset from the NGRIP ice core, and it is at all times based on 3-7 simultaneous records. An uncertainty estimate for the time scale is given based on the estimated counting error resulting from ambiguous features in the data, insufficient data resolution and occasional data gaps in some of the records. The $1 \sigma$ uncertainty is 828 years for the oldest year of the time scale, $41,761 \mathrm{yr}$ b2k, corresponding to an overall $1 \sigma$ uncertainty of about $2 \%$ over the past $42 \mathrm{ka}$. The differential dating uncertainty is small, and the length of most stadial-interstadial variations is determined with an uncertainty of less than a century. The annual layer thicknesses within similar climatic states are lognormally distributed, and the probability of individual layers being either narrower than half the average thickness or wider than twice the average thickness is less than $2.2 \%$. This together with the good agreement with the GISP2 stratigraphy over the very cold MIS2 period indicates that there is no significant hiatus of annual layers in the NGRIP ice core. The annual accumulation rate during the stadial/ interstadial periods of the investigated time interval was one third/one half of the present day value.

Table 2

Comparison between the flow corrected layer thicknesses for the shown intervals in Fig. 7 and the corresponding Fig. 9 in Rasmussen et al. (2006)

\begin{tabular}{lllrl}
\hline Period & NGRIP depth $(\mathrm{m})$ & $\lambda_{\text {corr }}$ interval $(\mathrm{cm})$ & Median $\lambda_{\text {corr }}(\mathrm{cm})$ & 19 \\
\hline Present $^{\mathrm{a}}$ & & - & 14.1 & $\lambda_{\text {corr }} / \lambda_{\text {present }}$ \\
Early Holocene $^{\mathrm{b}}$ & $1404-1490$ & - & 6.6 & 1 \\
YD $^{\mathrm{a}}$ & $1495-1523$ & - & 12.6 & 0.74 \\
Bølling $^{\mathrm{b}}$ & $1576-1603$ & - & 6.2 & 0.35 \\
GS-2 $^{\mathrm{c}}$ & $1620-1780$ & $3<\overline{\lambda_{\text {corr }}}<7$ & 5.5 & 0.37 \\
GS-3 to GS-10 $^{\mathrm{c}}$ & $1791-2128$ & $9<\overline{\lambda_{\text {corr }}}<12$ & 10.1 & 0.29 \\
GI-3 to GI-10 & $1791-2128$ & $\mathrm{c}$ & 0.56 \\
\hline
\end{tabular}

All layer thicknesses have here been strain corrected using the NGss06bm model, and $\overline{\lambda_{\text {corr }}}$ denotes the 20 years running mean of $\lambda_{\text {corr }}$.

${ }^{\mathrm{a}}$ From (NGRIP Members, 2004).

${ }^{\mathrm{b}}$ As defined for Fig. 9 in (Rasmussen et al., 2006).

${ }^{\mathrm{c}}$ As defined in Fig. 7. 
The stratigraphic dating of the NGRIP ice core is now being continued back to $60 \mathrm{ka} \mathrm{b} 2 \mathrm{k}$ (GI-17) where annual layers become marginal to be identified using the existing records. Preliminary investigations have, however, shown that the annual layers are still present at least back to $78 \mathrm{ka}$ b2k and may be counted using higher resolution records.

\section{Online data access}

Twenty year mean values of NGRIP $\delta^{18} \mathrm{O}$ data on the GICC05 time scale (as shown in Fig. 6) can be downloaded from http://www.icecores.dk.

\section{Acknowledgements}

This work is a contribution to the NorthGRIP ice core project, which is directed and organized by the Ice and Climate Research Group at the Niels Bohr Institute, University of Copenhagen. It is being supported by funding agencies in Denmark (SNF), Belgium (FNRSCFB), France (IFRTP and INSU/CNRS), Germany (AWI), Iceland (RannIs), Japan (MEXT), Sweden (SPRS), Switzerland (SNF) and the United States of America (NSF). This work is also a contribution to the Copenhagen Ice Core Dating Initiative, which is supported by a grant from the Carlsberg Foundation.

\section{Appendix A. Model Timescales}

The ss09sea timescale (Johnsen et al., 2001) in Fig. 1 has been applied to both the GRIP and NGRIP ice core records, but modified to account for basal melting at the NGRIP site. The ss09sea timescale for the GRIP ice core is a glaciological time scale where the accumulation model is based on the GRIP isotopic values corrected for the ocean isotopic history (Waelbroeck et al., 2002). The ice flow model was described by Johnsen and Dansgaard (1992) (note the errata), and the parameters used for GRIP are as follows: $H=3003.65 \mathrm{~m}$ of ice equivalent, $h=1500 \mathrm{~m}$, $d h=6.0 \mathrm{~m}, f b=0.17, f_{s}=0$ and the mean velocity in the silty layer is $50 \%$ of the velocity at the top of that layer. The accumulation model uses 5 point running means of the $0.55 \mathrm{~cm}$ (bag) mean $\delta^{18} \mathrm{O}$ values as input. The model

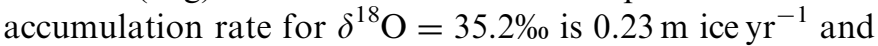
the relative changes in the accumulation rates, $\Delta$ acc/acc, for $1 \%$ change in $\delta^{18} \mathrm{O}$ are $8 \%$ and $18 \%$ for $\delta^{18} \mathrm{O}$ equal to $-35.2 \%$ and $-40.0 \%$, respectively.

The GRIP ss09sea time scale was transferred to the NGRIP core by (i) identifying 44 common time markers in both cores based on either volcanic events or sharp isotopic transitions (ii) designing a model time scale for the NGRIP core (NGss06bm) that is very close to the GRIP time scale by using a similar accumulation rate model and accounting for $6.7 \mathrm{~mm}$ of ice $\mathrm{yr}^{-1}$ bottom melting and (iii) by assigning GRIP ages to the time markers and linearly interpolating between them on the NGRIP time scale. The bottom of the NGRIP 2003 core at $3085.0 \mathrm{~m}$ was given the age of 123,000 years BP (before 1950) based on correlation with the Iberian margin MD95-2042 sediment core (Shackleton et al., 2000).

\section{References}

Alley, R.B., Shuman, C.A., Meese, D.A., Gow, A.J., Taylor, K.C., Cuffey, K.M., Fitzpatrick, J.J., Grootes, P.M., Zielinski, G.A., Ram, M., Spinelli, G., Elder, B., 1997. Visual-stratigraphic dating of the GISP2 ice core: basic, reproducibility, and application. Journal of Geophysical Research 102, 26367-26381.

Andersen, K.K., Ditlevsen, P.D., Rasmussen, S.O., Clausen, H.B., Vinther, B.M., Johnsen, S.J., 2006. Retrieving a common accumulation record from Greenland ice cores for the past 1800 years. Journal of Geophysical Research 111, D15106.

Beer, J., Finkel, R.C., Bonani, G., Gäggeler, H., Görlach, U., Jacob, P., Klockow, D., C. C. Langway, J., Neftel, A., Oeschger, H., Schotterer, U., Schwander, J., Siegenthaler, U., Suter, M., Wagenbach, D., Wölfli, W., 1991. Seasonal variations in the concentration of ${ }^{10} \mathrm{Be}, \mathrm{Cl}^{-}, \mathrm{NO}_{3}^{-}$, $\mathrm{SO}_{4}^{2-}, \mathrm{H}_{2} \mathrm{O}_{2},{ }^{210} \mathrm{~Pb},{ }^{3} \mathrm{H}$, mineral dust, and $\delta^{18} \mathrm{O}$ in Greenland snow. Atmospheric Environment 25A, 899-904.

Bender, M., Sowers, T., Dickson, M.-L., Orchardo, J., Grootes, P., Mayewski, P.A., Meese, D.A., 1994. Climate correlations between Greenland and Antarctica during the last 100,000 years. Nature 372, 663-666.

Bigler, M., 2004. Hochauflösende Spurenstoffmessungen an polaren Eisbohrkernen: Glazio-chemische und klimatische Prozessstudien. Unpublished Ph.D. dissertation thesis, University of Bern, Switzerland.

Björck, S., Walker, M.J.C., Cwynar, L.C., Johnsen, S., Knudsen, K.-L., Lowe, J.J., Wohlfarth, B., and INTIMATE Members, 1998. An event stratigraphy for the Last Termination in the North Atlantic region based on the Greenland ice-core record: A proposal by the INTIMATE group. Journal of Quaternary Science 13, 282-292.

Bromwich, D.H., Toracinta, E.R., Wei, H., Oglesby, R.J., Fastook, J.L., Hughes, T.J., 2004. Polar MM5 simulations of the winter climate of the Laurentide Ice Sheet at the LGM. Journal of Climate 17, 3415-3433.

Dahl-Jensen, D., Gundestrup, N., Miller, H., Watanabe, O., Johnsen, S.J., Steffensen, J.P., Clausen, H.B., Svensson, A., Larsen, L.B., 2002. The NorthGRIP deep drilling program. Annals of Glaciology 35, 1-4.

EPICA community members, 2004. Eight glacial cycles from an Antarctic ice core. Nature 429, 623-628.

GRIP Members, 1993. Climate instability during the last interglacial period recorded in the GRIP ice core. Nature 364, 203-208.

Hammer, C.U., 1980. Acidity of polar ice cores in relation to absolute dating, past volcanism, and radio-echoes. Journal of Glaciology 25, 359-372.

Hammer, C.U., Clausen, H.B., Dansgaard, W., Gundestrup, N., Johnsen, S.J., Reeh, N., 1978. Dating of Greenland ice cores by flow models, isotopes, volcanic debris, and continental dust. Journal of Glaciology 20, 3-26.

Johnsen, S.J., Dansgaard, W., 1992. On flow model dating of stable isotope records from Greenland ice cores. In: Bard, E., Broecker, W.S. (Eds.), The Last Deglaciation: Absolute and Radiocarbon Chronologies. Springer, New York, pp. 13-24 NATO ASI Ser. I.

Johnsen, S.J., Dahl-Jensen, D., Gundestrup, N., Steffensen, J.P., Clausen, H.B., Miller, H., Masson-Delmotte, V., Sveinbjörnsdottir, A.E., White, J., 2001. Oxygen isotope and palaeotemperature records from six Greenland ice-core stations: Camp Century, Dye-3, GRIP, GISP2, Renland and NorthGRIP. Journal of Quaternary Science 16, 299-307.

Krinner, G., Genthon, C., Jouzel, J., 1997. GCM analysis of local influences on ice core delta signals. Geophysical Research Letters 24, 2825-2828.

Lotter, A.F., Lemcke, G., 1999. Methods for preparing and counting biochemical varves. Boreas 28, 243-252. 
Meese, D., Alley, R., Fiacco, J., Germani, M., Gow, T., Grootes, P., Illing, M., Mayewski, P., Morrison, M., Ram, M., Taylor, K., Yang, Q., Zielinski, G., 1994. Holocene time scale and accumulation profile of the GISP2 core. CRREL Pub. SR94-01.

Meese, D.A., Gow, A.J., Alley, R.B., Zielinski, G.A., Grootes, P.M., Ram, M., Taylor, K.C., Mayewski, P.A., Bolzan, J.F., 1997. The Greenland Ice Sheet Project 2 depth-age scale: Methods and results. Journal of Geophysical Research 102, 26411-26423.

NGRIP Members, 2004. High resolution Climate Record of the Northern Hemisphere reaching into the last Glacial Interglacial Period. Nature 431, 147-151.

Petit, J.R., Jouzel, J., Raynaud, D., Barkov, N.I., Barnola, J.-M., Basile, I., Bender, M., Chappellaz, J., Davis, M., Delaygue, G., Delmotte, M., Katlyakov, V.M., Legrand, M., Lipenkov, V.Y., Lorius, C., Pépin, L., Ritz, C., Saltzman, E., Stievenard, M., 1999. Climate and atmospheric history of the past 420,000 years from the Vostok ice core, Antarctica. Nature 399, 429-436.

Ram, M., Koenig, G., 1997. Continuous dust concentration profile of preHolocene ice from the Greenland Ice Sheet Project 2 ice core: dust stadials, interstadials, and the Eemian. Journal of Geophysical Research 102, 26641-26648.

Rasmussen, S.O., Andersen, K.K., Svensson, A.M., Steffensen, J.P., Vinther, B.M., Clausen, H.B., Siggaard-Andersen, M.-L., Johnsen, S.J., Larsen, L.B., Dahl-Jensen, D., Bigler, M., Röthlisberger, R., Fischer, H., Goto-Azuma, K., Hansson, M.E., Ruth, U., 2006. A new Greenland ice core chronology for the last glacial termination. Journal of Geophysical Research 111, D06102.

Ruth, U., Wagenbach, D., Steffensen, J.P., Bigler, M., 2003. Continuous record of microparticle concentration and size distribution in the central Greenland NGRIP ice core during the last glacial period. Journal of Geophysical Research 108, 4098.

Röthlisberger, R., Bigler, M., Hutterli, M., Sommer, S., Stauffer, B., Junghans, H.G., Wagenbach, D., 2000. Technique for continuous high-resolution analysis of trace substances in firn and ice cores. Environmental Science \& Technology 34, 338-342.

Shackleton, N.J., Hall, M.A., Vincent, E., 2000. Phase relationships between millennial-scale events 64,000-24,000 years ago. Paleoceanography $15,565-569$.
Southon, J., 2004. A radiocarbon perspective on Greenland ice-core chronologies: can we use ice cores for $14 \mathrm{C}$ calibration? Radiocarbon 46, 1239-1259.

Steffensen, J.P., 1988. Analysis of the seasonal variation in dust, $\mathrm{Cl}^{-}$, $\mathrm{NO}_{3}^{-}$, and $\mathrm{SO}_{4}^{2-}$ in two Central Greenland firn cores. Annals of Glaciology 10, 171-177.

Svensson, A., Andersen, K.K., Bigler, M., Clausen, H. B., Dahl-Jensen, D., Davies, S.M., Johnsen, S.J., Muscheler, R., Rasmussen, S.O., Röthlisberger, R., Steffensen, J.P., and Vinther, B.M., 2006. The Greenland Ice Core Chronology 15-42 kyr. Part 2: comparison to other records. Quaternary Science Reviews, this issue, doi:10.1016/ j.quascirev.2006.08.003.

Svensson, A., Nielsen, S.W., Kipfstuhl, S., Johnsen, S.J., Steffensen, J.P., Bigler, M., Ruth, U., Röthlisberger, R., 2005. Visual stratigraphy of the North Greenland Ice Core Project (NorthGRIP) ice core during the last glacial period. Journal of Geophysical Research 110, D02108.

Vinther, B.M., Clausen, H.B., Johnsen, S.J., Rasmussen, S.O., Andersen, K.K., Buchardt, S.L., Dahl-Jensen, D., Seierstad, I.K., SiggaardAndersen, M.-L., Steffensen, J.P., Svensson, A.M., Olsen, J., Heinemeier, J., 2006. A synchronized dating of three Greenland ice cores throughout the Holocene. Journal of Geophysical Research 1, 111.

Waelbroeck, C., Labeyrie, L., Michel, E., Duplessy, J.C., McManus, J.F., Lambeck, K., Balbon, E., Labracherie, M., 2002. Sea-level and deep water temperature changes derived from benthic foraminifera isotopic records. Quaternary Science Research 21, 295-305.

Walker, M.J.C., Björck, S., Lowe, J.J., Cwynar, L.C., Johnsen, S., Knudsen, K.-L., Wohlfarth, B., and INTIMATE GROUP, 1999. Isotopic "events" in the GRIP ice core: A stratotype for the Late Pleistocene, Quaternary Science Reviews 18, 1143-1150.

Werner, M., Mikolajewicz, U., Heimann, M., Hoffmann, G., 2000. Borehole versus isotope temperatures on Greenland: seasonality does matter. Geophysical Research Letters 27, 723-726.

Whitlow, S., Mayewski, P.A., Dibb, J.E., 1992. A comparison of major chemical species seasonal concentration and accumulation at the South Pole and Summit, Greenland. Atmospheric Environment 26A, 2045-2054. 